\title{
Translation and Impersonation
}

Anne Malena

University of Alberta

\section{Introduction}

The theme for this third volume of TranscUlturAl was inspired by the annual colloquium in celebration of International Translation Day on September 30, 2009 at the University of Alberta. The response to our calls for papers was enthusiastic and, as the selection of articles included here shows, rather varied, the reason being that the term impersonation led to many levels of interpretation. This was no surprise as we always seek to generate debate for both the annual colloquium and the journal. We also strive to reach as wide an audience as possible and, in particular practitioners who don't always find suitable forums to express their views and their theoretical knowledge about their own practice. This is, therefore, how we presented the theme: "Whether you consider translation a relatively straightforward transfer from one language to another, a desirable means to put cultures in contact with each other, an impossible task that masochistic translators everywhere nevertheless persist in attempting, a necessary evil imposed by globalization, an imperialist tool or an instrument of peace, a duty, a dirty secret, a faulty means of communication, an art, an acquired skill, or a complex practice navigating the treacherous waters of all of the above, you may never have thought of it as impersonation". Contributors took up the challenge and reflected on the impersonating power of translation from different perspectives. Most probably started out by checking the term in various dictionaries, as translators are wont to do and as it was suggested in our call for papers: The Oxford English Dictionary online (http://www.oed.com.login.ezproxy.library.ualberta.ca/) offers these simple definitions: 1. The action of impersonating or fact of being impersonated; representation in personal or bodily form; personification; b. concr. An instance of this; a person or thing impersonating or representing a principle, idea, etc.; 2 . The dramatic representation of a character. 
Since all of these point to the "personification" of an idea or a character, that is to the persons of the impersonator and partly of the impersonated, our theme will have to consider both the person of the translator as impersonator and the "thing" of translation as impersonation. In this framework translation also becomes performance and the translator a performer of the skills required and acquired for his or her practice. We know of pseudo-translations and of fictional translators, oftentimes brilliant literary impersonations, but what of the mostly invisible translator, in many walks of life, briefly impersonating authors in order to produce more or less evanescent impersonations of the source texts they have been trusted with? What can we learn from thinking about translation in these terms?" The response was a colourful array of perspectives that all dealt more or less explicitly with some of the issues suggested above. It is with great pride then that we offer this collection of seven essays as a way to continue celebrating translation and translators.

David Solway, who delivered the keynote address at the colloquium and who is arguably the best Canadian poet today, opens with "Getting from Here to There", provocatively calling translation "an exercise in brave futility", and yet demonstrating how significant the etymological "carrying over" of translation can be. As the translator of the Greek poet Andrea Karavis (Saracen Island 2000) and as a poet himself, Solway is familiar with the failure of language to communicate exactly what we mean but also with our very human desire to transcend that impossibility and even ourselves. For him "translation, as a discipline, is the very incarnation of metaphor". And the process of translating is a crossover that transforms the translator into another self, a writing self. In the last part of his essay the poet/translator/poet illustrates these ideas with a commentary on the poetry and translation of Karavis, one of his most intriguing impersonations.

We then move to the issue of "fake" translations with a short but powerful piece on international impersonations of Harry Potter by Lynn Penrod. The impersonation of an "original" through 
"unauthorized" or "fake" translation raises complex issues of cultural and political ideology because the author and her bestselling creation are displaced and subverted for the sake of something new and culturally resonant.

No author has fought harder against this sort of displacement, albeit interestingly not due to unauthorized translations, than the Czech writer Milan Kundera, as is discussed in the third essay by Miriam Margala. Residing in France, and now often writing in French, Kundera has had many occasions to complain about his translators and their work because no one can approximate the authenticity of his novels. Beyond demonstrating that Kundera as a writer impersonates God, Margala takes us on a very interesting journey to show that Kundera's obsession with authenticity and his frequent manipulations of supposedly trustworthy translations amount to a paradox: the displacement of the author is inevitable because everything is translation.

The next contribution by Regina Galasso also deals with questioning boundaries of authorship but this time the author himself, the Spanish-born Felipe Alfau writing in English, imagines a translator as the narrator of his novel Chromos. The result is a novel impersonating a translation through the depiction of a relationship of co-dependence between translator and author. This portrayal of the translator as a co-author in turn shows that in today's multicultural world translation may always be a part of literary creation.

The article by Isabelle Collombat that follows argues that impersonation can also be viewed as a complex form of rational empathy. This article stems from the semantic gap existing between English and French definitions of the term impersonator, which has no easy translation in French. Personnificateur offers an imperfect description of "dissolution de soi", which is part of the translator's impersonation of the author and puts too much emphasis on the author at the expense of the reader. Basing her discussion on the concept of rational empathy by the philosopher Benoit 
Huffschmidt, Collombat reminds us that the translator is first a reader, which makes him or her empathetic toward the text and future readers as well as the author.

Chris Reyns-Chikuma looks at fictional translation and issues pertaining to the contemporary world in his analysis of the figure of a female interpreter in the novel Constellation (2008) by French writer Alain Lacroix. He shows how, in spite of being assigned a minor role-which, of course, could be simply termed realistic — she has a haunting sexual and ideological presence in the text. In a novel that can be seen as a representation of the "supranationality" of Europe, this character functions as an impersonation of Europe and of the inherent ambivalence of the European project.

The concluding essay by Zeb Raft brings us back to poetry, this time in China and intricately linked to music. Although it remains implicit in the piece one could view Eunice Tietjens, the translator presented here, as an impersonator of Chinese poetry. Her use of western musical notation to transcribe the chant of a short poem by two Chinese scholars and her own poetic sketches following a visit to China in 1916 mark her as one not afraid to subvert boundaries but at the same time expose her own limitations caused by the inevitable distance between what she heard and saw and what she created as a result.

This collection is a first attempt to tease out some of the issues evoked by the theme of translation and impersonation. We very much hope that readers will find it as productive as we did and feel free to send in comments and suggestions for further investigation into the important role that translators and their craft play in today's literary world and beyond, including our increasingly complex networks of communication. If revolutions can be initiated and managed on twitter can we really afford not to consider, or reconsider rather, age-old questions of who speaks for whom, who represents whom, who writes and who translates? As all the articles in this volume show that translation is of the utmost importance when it comes to gaining a better understanding of 
TranscUlturAl, vol.1.3 (2010), 1-5.

http:/ / ejournals.library.ualberta.ca/index.php/TC

authorship and representation and, since writers themselves engage in the problematics of translation by translating, creating translator characters, producing pseudo-translations or impersonating other writing selves through translation, the time is ripe to subvert the accepted notion of the translator as a humble, silent and invisible figure behind the writer in the equations of creation and communication. This "call to arms" is not new but is most valuable when repeated incessantly. 